\title{
Electrochemical Studies of Derivatized Thiol Self-Assembled Monolayers on Gold Electrode in the Presence of Surfactants
}

\author{
Liu YANG, Wanzhi WeI, ${ }^{\dagger}$ Jianjun XIA, Han TAO, and Pinghua YANG \\ State Key Laboratory of Chemical, Biological Sensing Technologies \& Chemometrics, Hunan University, \\ Changsha, 410082, People's Republic of China
}

\begin{abstract}
Electrochemical impendence spectroscopy (EIS), cyclic voltammetry (CV) and differential pulse voltammetry (DPV) were performed to investigate the barrier properties and electron transfer of derivatized thiol self-assembled monolayers (SAMs) on gold in the presence of surfactants. The thiol derivatives used included 2-mercaptoethanesulfonic acid (MES), 2-mercaptoacetic acid (MAA), and $N$-acetyl-L-cysteine (NAC). A simple equivalent circuit was derived to fit the impedance spectra very well. The negative redox probe $\left[\mathrm{Fe}(\mathrm{CN})_{6}\right]^{3-14}$ was selected to indicate the electron-transfer efficiency on the interface of the studied electrodes. It was found that by changing the surface structure of SAMs, different surfactants could regulate the barrier properties and electron-transfer efficiency in different ways. A positively charged surfactant lowered the electrostatic repulsion between the negative redox probe and negatively charged surface groups of a monolayer, while enhancing the reversibility of electron transfer by virtue of increasing the redox probe concentration within the electric double-layer region. A neutral surfactant showed no significant effect, while a negative surfactant hindered the access and reaction of redox probe by electrostatic repulsion of same-sign charges.
\end{abstract}

(Received September 22, 2004; Accepted February 10, 2005)

\section{Introduction}

In the last decade, self-assembled monolayers (SAMs) of thiol derivatives on gold were proved to be a versatile model system for electrochemists, since they enable electrode surfaces to be modified in a well defined and reproducible way and to build up molecular architectures on the surfaces. ${ }^{1}$ Fundamental studies in electron transfer, ${ }^{2-4}$ electrochemical sensors $^{5-7}$ and electrochemical surface science in general $^{8}$ were performed using these systems.

The electron-transfer and ion-penetration behaviors of thiol derivative SAMs are among the research interests ${ }^{9-12}$ in the area of interface science. Long alkyl chain thiol derivatives, such as dodecanethiol (DDT), were selected to fill the defects of a capacitive transducer of an immunosensor. ${ }^{13}$ Moreover, short alkyl chains thiol derivatives, for instance mercaptoacetic acid (MAA), mercaptoethane sulfonate (MES) and mercaptopropionic acid (MPA), were used to form porous disorganized monolayers on gold for the detection of copper in complex samples. ${ }^{14}$ Therefore, it is necessary to investigate the electron-transfer and penetration properties of different SAMs under specific conditions. The orientation and barrier properties of SAMs of hexanedithiol, octanedithiol and 1,4-benzene dimethanethiol on gold in acetonitrile were studied by Sur et $a l .{ }^{15}$ They concluded that the latter could form more organized monolayers on gold than aliphatic dithiol SAMs. An impedance method to evaluate the ionization of acidic and basic groups in surface confined monomolecular films was reported by

$\dagger$ To whom correspondence should be addressed.

E-mail:weiwz2003@126.com
Schweiss ${ }^{16}$ and his colleagues. Takehara et al. ${ }^{17-20}$ carried out seriate studies by cyclic voltammetry $(\mathrm{CV})$ on the permeation properties regulated by the solution $\mathrm{pH}$ value, lanthanide and alkaline earth metal ions on glutathione and cysteine-containing dipeptide monolayer modified gold electrode. However, the experimental techniques that they used were not the best choice.

Surfactants were found to play important roles in the biological process. For instance, the alveolar cells of the lung can secrete a surfactant to maintain the stability of pulmonary tissue by reducing the surface tension of fluids that coat the lung. ${ }^{21,22}$ Furthermore, surfactants may strongly effect the conformation of the polypeptide chain. ${ }^{23}$ Surfactants can also be used to facilitate the study of transmembrane proteins ${ }^{24}$ and to mimic the properties of a cationic lipid. ${ }^{25}$ In the field of electroanalysis, surfactants have been found to change the electron transfer of electroactive species at a bare metal electrode. For example, hexadecyl pyridine bromide (HPB) can improve the electron-transfer rate of hemoglobin at a bare silver electrode. ${ }^{26}$ Cetyltrimethylammonium bromide (CTMAB) formed on an electrode surface can change the dissolution mechanism of copper under acidic conditions. ${ }^{27}$ A didodecyldimethylammonium bromide (DDAB) multilayer modified pyrolytic graphite electrode was used to investigate the electrochemical behavior of spinach ferredoxin and multiheme. ${ }^{28}$ The adsorbed myoglobin on a DDAB-modified graphite electrode can provide even more distinct peaks on the CV profiles. ${ }^{29}$ Alternately, Tsai et al. ${ }^{30}$ reported that surfactants could cause a deleterious effect on the cadmium peak during the stripping voltammetric detection of cadmium. The influence of an ionic surfactant on the Au-colloid modified electrode function was studied by Liu et al..$^{31}$ The results indicated that various surfactants exhibit different behaviors. However, the 


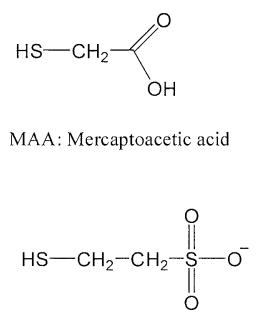

MES: Mercaptoethane sulfonate

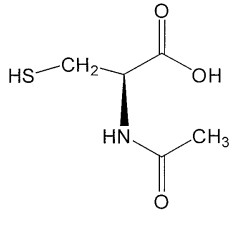

NAC: N-Acetyl-L-cysteine
Fig. 1 Structures of thiol reagents used for electrode modification.

electron transfer at a thiol derivatives modified electrode with coexisting surfactants has not received much attention, and results concerning this matter are somewhat inconclusive. ${ }^{32}$

Electrochemical impedance spectroscopy (EIS) has proved to be a valuable technique in extensive application areas, such as electrode kinetics, membranes, conducting polymers, semiconductors, surface treatment, batteries and fuel cells. Especially, in the research of interface phenomena, even using a simple electrolyte, EIS can provide much more prolific information about the stability of SAMs, their barrier properties and the degree of perfection than traditional electrochemical techniques.

In this paper, by using EIS, CV and differential pulse voltammetry (DPV), the effects of surfactants on the barrier properties of SAMs were considered based on the interaction mode between the head groups of a derivatized thiol molecule and of surfactants. The electron-transfer kinetics of a redox probe was measured to evaluate the barrier properties of SAMs in the presence of a surfactant.

\section{Experimental}

\section{Materials}

MAA and MES were obtained from Sigma. N-Acetyl-Lcysteine (NAC) was purchased from Shanghai Biochemical Reagent Co. (Shanghai, China). Their chemical structures are shown in Fig. 1. Hexadecyl pyridine bromide (HPB), hexadecyl trimethylammonium bromide (HTAB), sodium dodecyl benzene sulfonate (SDBS) and Tween-80 were provided by Beijing Chemical Reagent Factory (Beijing, China). Ionic surfactants were recrystallized prior to use. Other chemicals were of analytical grade or better. Solutions were prepared with doubledistilled water.

\section{Electrode pretreatment}

A gold disk electrode $(2.0 \mathrm{~mm}$ in diameter; $\mathrm{CH}$ Instruments, Inc., USA) was polished with $\alpha-\mathrm{Al}_{2} \mathrm{O}_{3}$ power (first with $1.0 \mu \mathrm{m}$, then $0.3 \mu \mathrm{m}$, and finally with $0.05 \mu \mathrm{m}$ power) slurries on a 1200 grit Carbimet disk until a mirror shiny surface appeared, and was then sequentially sonicated in methanol and double distilled water for $3 \mathrm{~min}$ to remove trace alumina. To ensure a clean surface, the polished electrode was subject to a cycling potential between 0 and $1.5 \mathrm{~V}$ in $0.5 \mathrm{M} \mathrm{H}_{2} \mathrm{SO}_{4}$ until reproducible cyclic voltammograms were obtained. ${ }^{14}$

\section{Electrode modification}

The SAMs of NAC were obtained by immersing clean electrodes in aqueous solutions containing $5 \mathrm{mM}$ NAC overnight. MES and MAA monolayer modified electrodes were prepared by overnight deposition from $5 \mathrm{mM}$ solutions of the

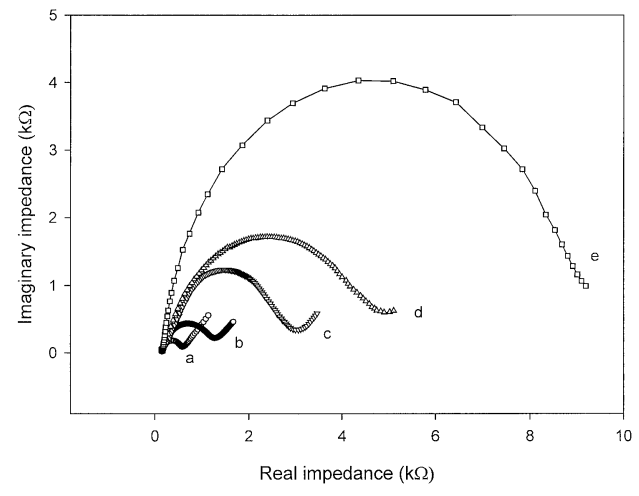

Fig. 2 Nyquist plots of EIS with a MAA/Au electrode in a $1 \mathrm{mM}$ $\left[\mathrm{Fe}(\mathrm{CN})^{3-4-}\right.$ probe solution containing different concentrations of HPB. (a) Without HPB; (b) $10^{-4} \mathrm{~mol} / \mathrm{L}$; (c) $5 \times 10^{-5} \mathrm{~mol} / \mathrm{L}$; (d) $10^{-5}$ $\mathrm{mol} / \mathrm{L}$; (e) $5 \times 10^{-6} \mathrm{~mol} / \mathrm{L}$. The bias potential is $0.17 \mathrm{~V}$. Data points from left to right correspond to decreasing frequency.

corresponding thiols in ethanol solutions. In the self-assemble procedure, the environmental temperature was maintained at $4^{\circ} \mathrm{C}$. The resulting electrodes were thoroughly rinsed with the corresponding solvent, dried in a nitrogen stream and then immediately mounted in an electrochemical cell.

\section{Electrochemical measurement}

EIS, CV and DPV were performed using a $\mathrm{CH}$ Instruments Model 660A electrochemical workstation (Shanghai Chenhua Apparatus Co.) with CHI software, connecting to a personal computer and with a standard three-electrode system. EIS was performed in a $1 \mathrm{mM} \mathrm{K} 3\left[\mathrm{Fe}(\mathrm{CN})_{6}\right] / \mathrm{K}_{4}\left[\mathrm{FeCN}_{6}\right]$ (1:1) solution containing $0.1 \mathrm{M} \mathrm{KCl}$ and corresponding surfactants. The impedance spectra were measured from $1 \mathrm{~Hz}$ to $100 \mathrm{kHz}$ with an amplitude of $\pm 5 \mathrm{mV}$. The impedance spectra were recorded in the form of Nyquist plots. Data fittings and simulations were performed using a frequency response analyzer (FRA, version 4.9, Eco Chemie, The Netherlands), according to the concept of Dr. B. A. Boukamp's so-called circuit description code (CDC).

All electrochemical measurements were carried out in $10-\mathrm{mL}$ glass cells at room temperature. Thiol derivative-modified electrodes were used as working electrodes. The potentials measured were vs. a saturated calomel electrode (SCE), and a platinum wire electrode was used as an auxiliary electrode. All of the glassware in a following experiment were immersed in a $0.1 \mathrm{M} \mathrm{HNO}_{3}$ solution overnight after being cleaned, and were then rinsed with double-distilled water and dried in air.

\section{Results and Discussion}

Electrochemical impedance spectroscopy characterization Impedance theory of SAM modified electrodes. In the absence of electroactive ions, the electrochemical impedance $Z$ of an electrode covered with a well-organized SAM can be interpreted by a simple equivalent circuit of the total interfacial capacitance in series with the solution resistance $\left(R_{\mathrm{s}}\right)$. In real electrochemical cells, the capacitance is commonly treated as a constant phase element (CPE) to average out effects, due to inhomogeneties. The impedance of such a non-ideal double layer is represented by

$$
Z_{\mathrm{CPE}}(\omega)=-j /(\omega Q)^{\mathrm{n}} .
$$


Table 1 Element values of the equivalent circuit $\mathrm{R}(\mathrm{Q}[\mathrm{RW}])$ obtained by a fitting program for bare $\mathrm{Au}, \mathrm{MAA} / \mathrm{Au}$ and $\mathrm{NAC} / \mathrm{Au}$ electrodes in electrolytes containing different concentrations of HPB

\begin{tabular}{|c|c|c|c|c|c|c|}
\hline \multicolumn{2}{|c|}{ Conc./mol L ${ }^{-1}$} & \multirow{2}{*}{$\begin{array}{l}R_{\mathrm{s}} / \Omega \\
146.8\end{array}$} & \multirow{2}{*}{$\begin{array}{c}C P E / \mu \mathrm{F} \\
28.2\end{array}$} & \multirow{2}{*}{$\frac{n}{0.8457}$} & \multirow{2}{*}{$\begin{array}{r}R_{\mathrm{et}} / \mathrm{k} \Omega \\
0.43\end{array}$} & \multirow{2}{*}{$\frac{Z_{\mathrm{w}} / \Omega}{9.13 \times 10^{-}}$} \\
\hline & 0 & & & & & \\
\hline & $10^{-4}$ & & & & & \\
\hline & $5 \times 10$ & & & & & \\
\hline & 10 & 147 & & 19 & 4.28 & \\
\hline & $5 \times 10^{-6}$ & 161.5 & 78.5 & 0.9402 & 7.8 & 2.18 \\
\hline & $10^{-4}$ & 148.9 & 38.2 & 0.89 & 4.42 & $4.53 \times 10^{-4}$ \\
\hline & $5 \times 10^{-5}$ & 150.2 & 342 & 0.90 & 5.08 & $3.65 \times$ \\
\hline & $10^{-5}$ & 152 & & 0.91 & 8.83 & 2.17 \\
\hline & $5 \times 10^{-6}$ & 153.9 & 33.3 & 0.89 & 12.32 & $1.58 \times 10^{-4}$ \\
\hline
\end{tabular}

The total impedance for a series combination is given by

$$
Z(\omega)=R_{\mathrm{s}}+\frac{1}{(j \omega)^{\mathrm{n}} C_{\mathrm{T}}}
$$

For an ideal capacitor, $n$ is equal to 1 . At very low frequencies the current is almost purely capacitive and the phase angles closely approach $90^{\circ} \mathrm{C}$. Ion permeation might occur on poorly assembled SAMs, thus increasing the capacitance and decreasing the phase angle at low frequency. ${ }^{33-35}$

For a series combination of a capacitor and a resistor, it is convenient to plot the admittance $Y\left(Y=Z^{-1}\right)$ normalized to the angular frequency $\omega=2 \pi f$ instead of the complex impedance $Z$ (Nyquist plot), since in this case the Nyquist plot just yields a rather, or less straight line intersecting the real axis $Z^{\prime}$ at $R_{\mathrm{s}}$. In the complex plane of the semicircle-shaped curve with an imaginary axis yields the capacitance, $C_{\mathrm{T}}$. Hence, a more expressive admittance plot is used to present our data. For the total interfacial capacitance (treated as a CPE) in series with $R_{\mathrm{s}}$, the real part of the admittance, $Y^{\prime}$, is represented by

$$
\frac{Y^{\prime}}{\omega}=\frac{R \omega^{2 \mathrm{n}} C_{\mathrm{T}}^{2}}{R^{2} \omega^{2 \mathrm{n}} C_{\mathrm{T}}^{2}+1}
$$

and the imaginary part by

$$
\frac{Y^{\prime \prime}}{\omega}=j \times \frac{C_{\mathrm{T}}}{R^{2} \omega^{2 \mathrm{n}} C_{\mathrm{T}}^{2}+1} .
$$

Equivalent circuit of a thiol SAMs modified electrode. A Nyquist diagram of electrochemical impedance spectrum is an effective way to measure the electron-transfer resistance. Figure 2 shows Nyquist plots of a MAA/Au electrode in the presence of a $1 \mathrm{mM}\left[\mathrm{Fe}(\mathrm{CN})_{6}\right]^{3-14}$ probe solution containing different concentrations of HPB in the range from $10^{-6}$ to $10^{-4}$ $\mathrm{mol} / \mathrm{L}$. As shown in Fig. 2, each of the impedance spectra includes a semicircle part and a linear line part, corresponding to the electron-transfer process and the diffusion process, respectively. The diameter of the semicircle represents the electron-transfer resistance $\left(R_{\mathrm{et}}\right)$ at the electrode surface.

The data of the electrochemical impedance spectra can be fitted by an equivalent-circuit model of the system. Based on the general electronic equivalent model of an electrochemical cell, an equivalent circuit that consists of the solution resistance $\left(R_{\mathrm{S}}\right)$ of the electrolyte between two electrodes and constant phase element $(\mathrm{CPE})$, electron transfer resistance $\left(R_{\mathrm{et}}\right)$, and Warburg impedance $\left(Z_{\mathrm{w}}\right)$ around each electrode, was derived to interpret the impedance measurement of thiol SAMs modified

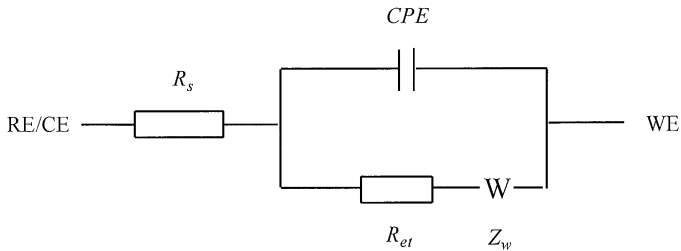

Fig. 3 Equivalent circuit $\mathrm{R}(\mathrm{Q}[\mathrm{RW}])$ of the electrochemical interface: (1) $R_{\mathrm{s}}$, solution resistance; (2) CPE, constant phase element; (3) $R_{\mathrm{et}}$, electron transfer resistance; (4) $Z_{\mathrm{w}}$, Warburg impedance. RE, CE, WE represent reference electrode, counter electrode and working electrode, respectively.

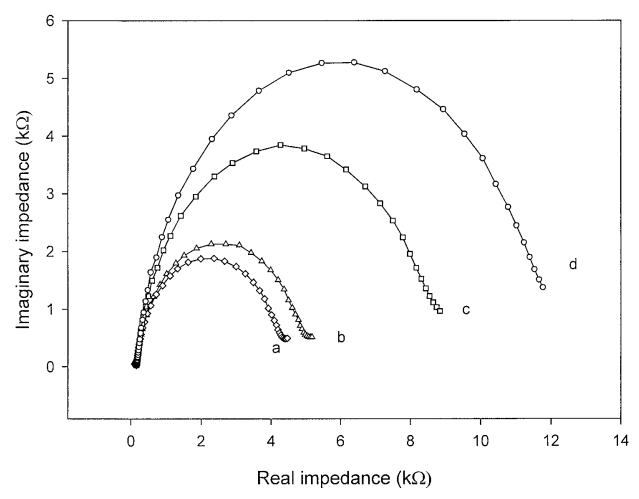

Fig. 4 Nyquist plots of EIS with a NAC/Au electrode in a $1 \mathrm{mM}$ $\left[\mathrm{Fe}(\mathrm{CN})_{6}\right]^{3-14-}$ probe solution containing different concentrations of $\mathrm{HPB}$. (a) $10^{-4} \mathrm{~mol} / \mathrm{L}$; (b) $5 \times 10^{-5} \mathrm{~mol} / \mathrm{L}$; (c) $10^{-5} \mathrm{~mol} / \mathrm{L}$; (d) $5 \times 10^{-6}$ $\mathrm{mol} / \mathrm{L}$. The bias potential is $0.17 \mathrm{~V}$. Data points from left to right correspond to decreasing frequency.

electrodes. The CDC of this Randles' circuit with a CPE element instead of a pure double capacitance is $\mathrm{R}(\mathrm{Q}[\mathrm{RW}])$. The equivalent circuit is shown in Fig. 3. The two elements of the circuit, $R_{\mathrm{s}}$ and $Z_{\mathrm{w}}$ represent the bulk solution properties and the diffusion of the redox. They are not influenced by the reaction occurring at the electrode surface. CPE and $R_{\text {et }}$ depend on the insulating and barrier properties at the electrolyte/electrode interface. By fitting the electrochemical impedance spectra to the equivalent circuit, the value of each electrical element in the equivalent circuit was obtained, as shown in Table 1. In Fig. 2, curve (a) is a Nyquist plot of a bare gold electrode in $1 \mathrm{mM}$ $\left[\mathrm{Fe}(\mathrm{CN})_{6}\right]^{3-14-}$ without any surfactant. A very small semicircle domain $\left(R_{\mathrm{et}}=0.43 \mathrm{k} \Omega\right)$ was found, which implied a very low electron-transfer resistance to the redox probe. After a modification with MAA, the electron-transfer resistance reached a large value (not shown in the figures). From curve (e) to curve (b) (in Fig. 2), along with an increase of the HPB concentration from $5 \times 10^{-6}$ to $10^{-4} \mathrm{~mol} / \mathrm{L}$, the interfacial electron resistance decreased dramatically, which indicated that surfactant HPB facilitates the electron transfer of the electrochemical probe on the MAA monolayer modified electrode. As can also be seen, there was almost no change in $R_{\mathrm{s}}$, which demonstrated that it was not affected by a modification on the electrode surface.

Figure 4 presents Nyquist diagrams of the electrochemical impedance spectra of a NAC/Au electrode in a $1 \mathrm{mM}$ $\mathrm{K}_{3}\left[\mathrm{Fe}(\mathrm{CN})_{6}\right]+\mathrm{K}_{4}\left[\mathrm{Fe}(\mathrm{CN})_{6}\right]$ probe solution containing different concentrations of HPB. The element values were fitted, and are also shown in Table 1. After a modification, the electrontransfer resistance of NAC/Au was much higher than that of the 
Table 2 Electrochemical parameters obtained at a MAA/Au electrode in a $1.0 \mathrm{mM}\left[\mathrm{Fe}(\mathrm{CN})_{6}\right]^{3-14}$ probe solution containing different ionic surfactants.

\begin{tabular}{lcccccl}
\hline & $\begin{array}{c}C / 10^{-5} \\
\mathrm{~mol} \mathrm{~L}\end{array}$ & $E_{\mathrm{pc}} / \mathrm{V}$ & $E_{\mathrm{pa}} / \mathrm{V}$ & $\Delta E_{\mathrm{p}} / \mathrm{V}$ & $i_{\mathrm{p}} / \mu \mathrm{A}$ & $\begin{array}{l}k_{\mathrm{s}} / 10^{-6} \\
\mathrm{~cm} \mathrm{~s}^{-1}\end{array}$ \\
\hline Bare Au & - & 0.211 & 0.141 & 0.070 & 11.8 & 9.41 \\
MAA $/ \mathrm{Au}$ & - & - & - & - & 0.827 & 0.827 \\
HTAB & 0.05 & 0.327 & -0.006 & 0.333 & 1.39 & 1.81 \\
& 0.1 & 0.332 & -0.014 & 0.346 & 1.33 & 1.60 \\
& 0.5 & 0.256 & 0.106 & 0.150 & 4.10 & 4.52 \\
& 1 & 0.215 & 0.137 & 0.078 & 10.7 & 8.46 \\
& 5 & 0.211 & 0.141 & 0.070 & 12.6 & 9.24 \\
HPB & 10 & 0.212 & 0.141 & 0.071 & 11.5 & 8.68 \\
& 0.05 & 0.318 & -0.003 & 0.321 & 1.38 & 2.03 \\
& 0.1 & 0.322 & -0.012 & 0.334 & 1.38 & 1.81 \\
& 0.5 & 0.267 & 0.074 & 0.193 & 3.06 & 4.33 \\
& 1 & 0.214 & 0.134 & 0.080 & 10.9 & 8.46 \\
SDBS & 5 & 0.211 & 0.135 & 0.076 & 11.6 & 8.71 \\
& 10 & 0.205 & 0.135 & 0.070 & 12.5 & 9.15 \\
& 0.05 & 0.266 & 0.055 & 0.211 & 2.78 & 3.72 \\
& 0.1 & 0.263 & 0.064 & 0.199 & 2.84 & 3.96 \\
& 0.5 & 0.274 & 0.048 & 0.226 & 2.30 & 3.32 \\
& 1 & 0.289 & 0.019 & 0.270 & 1.84 & 2.41 \\
& 5 & 0.352 & -0.070 & 0.422 & 0.856 & 1.15 \\
& 10 & 0.400 & -0.099 & 0.499 & 0.587 & 0.58 \\
\hline
\end{tabular}

$\left(\Delta E_{\mathrm{p}}=E_{\mathrm{pc}}-E_{\mathrm{pa}} ; E_{\mathrm{pc}}\right.$ and $E_{\mathrm{pa}}$ were obtained by $\mathrm{CV}$ (potential scan rate $50 \mathrm{mV} \mathrm{s}^{-1}$ ); $i_{\mathrm{p}}$ was measured by DPV (amplitude $0.05 \mathrm{~V}$, pulse width $0.05 \mathrm{~s}$, pulse period $0.2 \mathrm{~s}$ ); $k_{\mathrm{s}}$ values from EIS are the mean values of three successive measurements with relative deviation values smaller than $4 \%$.

MAA modified electrode, indicating that the NAC formed a denser and better ordered monolayer on the gold electrode than MAA. With an increase of the HPB (cationic surfactant) concentration, the electron-transfer resistance decreased from $12.32 \mathrm{k} \Omega$ to $4.42 \mathrm{k} \Omega$, and also minished the barrier effect of a self-assembled monolayer. In Table 1, the Warburg impedance is shown to decrease along with an increase of the surfactant concentration; at the same time, the electron transfer-resistance decreases, indicating that the electrochemical reaction that occurred on the electrode surface changed from diffusion control to electron transfer control.

Cyclic voltammetry and differential pulse voltammetry characterization

General barrier properties and surface structure of SAMs in the presence of surfactants. CV and DPV were also employed to investigate the barrier properties and electron transfer of a derivatized thiol SAMs modified electrode in the presence of surfactants.

Electrochemical experiments were performed in neutral solutions ( $\mathrm{pH}$ 6.8). In this acidity, MAA ( $K_{\mathrm{a}}=4.52$ on a gold electrode surface) ${ }^{36}$ NAC and MES have a negative net charge at a neutral $\mathrm{pH}$.

As shown in Table 2, compared to the bare gold electrode, the peak current $\left(i_{\mathrm{p}}\right)$ of the MAA modified electrode prominently decreased, along with an increase of the peak potential separation $\left(\Delta E_{\mathrm{p}}\right)$. This meant that a dense monolayer was selfassembled on the gold surface. When SDBS (anionic surfactant) was added to a redox probe solution, the peak current decreased further, revealing that SDBS shows some hindrance to the access of $\mathrm{Fe}(\mathrm{CN})_{6}^{3-14-}$ onto the MAA/Au electrode. However, in a cationic surfactant (HPB and HTAB) containing an electrolyte, the phenomena were contrary.
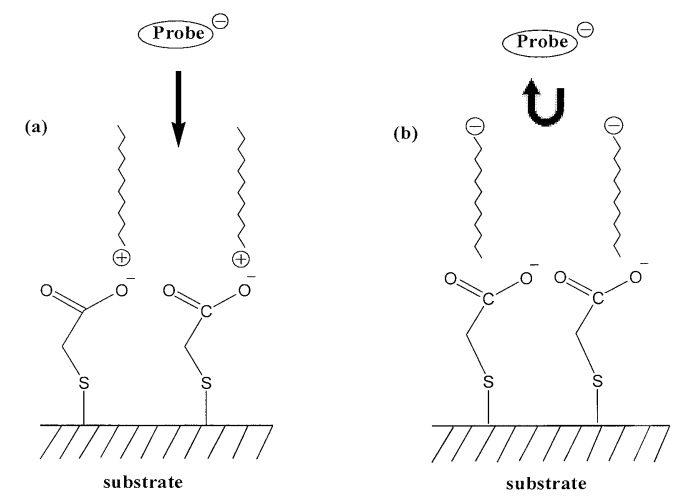

Fig. 5 Schematic graph of the surface structure of a MAA selfassembled monolayer and the response to (a) a cationic surfactant, (b) an anionic surfactant.

Compared with MES/Au, the residual currents on MAA and NAC modified electrodes were neglectable in the cyclic voltammograms, which show that except for MES/Au, the electron-transfer reaction on the electrode surface was efficiently hindered by MAA and NAC monolayers. This may be a stronger electrostatic repulsion of the terminal group of the MES-sulfo group, which prevents a compact and dense selfassembled monolayer from forming on the gold electrode. Only a loose and porous film was obtained. This film can hinder the access of macromolecules, for instance proteins, while a smallsize molecule, $\left[\mathrm{Fe}(\mathrm{CN})_{6}\right]^{3-14-}$ ion, can still penetrate and be reduced on the electrode surface.

A schematic diagram of the surface structure of a MAA monolayer on a gold surface in the presence of different surfactants is given in Fig. 5. The effect of the surfactant type on the barrier behavior can be interpreted by their structures. Because of an electrostatic attraction, the head group of a cationic surfactant was adsorbed on the carboxylate groups, which decreased the net negative charge on the MAA monolayer for neutralization. Therefore, the electrostatic repulsion between the MAA monolayer and $\mathrm{Fe}(\mathrm{CN}) 6^{3-14}$ ion was reduced, which eventually lead to an open channel in the MAA monolayer. Thus, better reversibility of the electrontransfer reaction at the MAA monolayer was observed in the presence of cationic surfactants. In contrast, negatively charged carboxylate groups repel the head groups of an anionic surfactant; then, the long alkyl chains of the anionic surfactant can intercalate into the MAA monolayer. This adsorption mode resulted in a denser membrane on a gold surface, which effectively hindered electron transfer.

Effect of a cationic surfactant. Significant electrochemical parameters, $\left(E_{\mathrm{pc}}, E_{\mathrm{pa}}\right.$ and $\left.\Delta E_{\mathrm{p}}\right)$ were obtained by cyclic voltammetry. The apparent heterogeneous rate constant $\left(k_{\mathrm{s}}\right)$ was obtained from EIS. These parameters were used to characterize the reversibility of a redox reaction on the electrode surface. Former studies of Porter et al..$^{37}$ and Meiller et al. ${ }^{38}$ proved that the compactness and sensitivity of a monolayer could be effectively probed by the redox behavior of a reversible couple. Therefore, the electron transfer efficiency of a monolayer can be evaluated by the kinetics of a redox probe, namely by the cathodal peak separation to the anodic peak $\left(\Delta E_{\mathrm{p}}\right)$. The electron-transfer efficiency on the monolayer can be characterized by the diversification of $\Delta E_{\mathrm{p}},{ }^{34}$ equal to the process in the presence of surfactants.

The electrochemical parameters of the MAA modified 


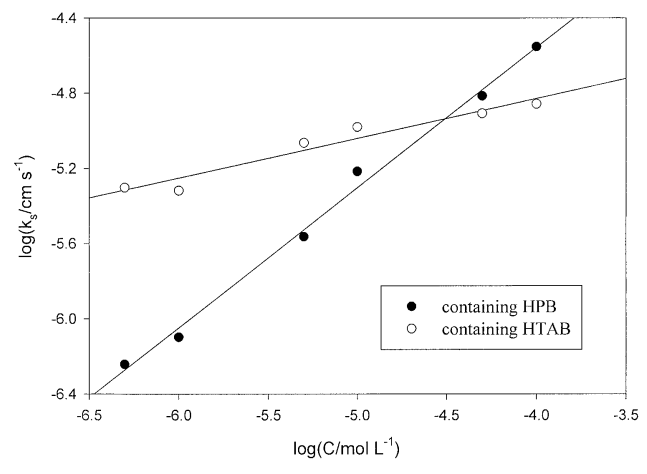

Fig. 6 Plot of $\log k_{\mathrm{s}}$ vs. $C$ (surfactant concentration) on a NAC modified gold electrode in a $\left[\mathrm{Fe}(\mathrm{CN})_{6}\right]^{3-14}$ system containing $0.1 \mathrm{M}$ $\mathrm{KCl}(0.170 \mathrm{~V} v s$. SCE $) ; k_{\mathrm{s}}$ values from EIS are the mean values of three successive measurements with relative deviation values smaller than $4 \%$.

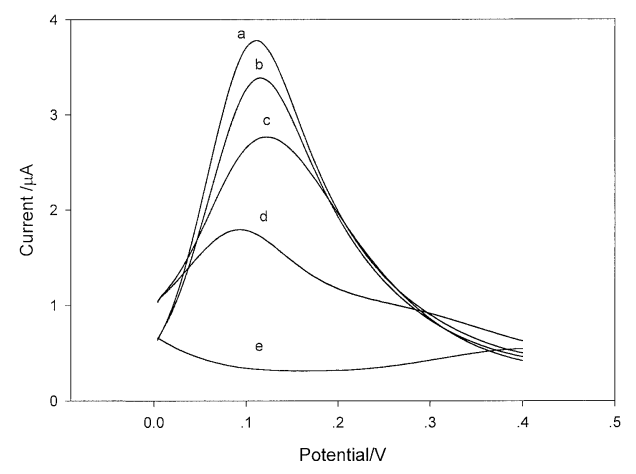

Fig. 7 Differential pulse voltammograms of $1 \mathrm{mM}\left[\mathrm{Fe}(\mathrm{CN})_{6}\right]^{3-14}$ measured with a NAC modified gold electrode in the presence of HTAB (amplitude, $0.05 \mathrm{~V}$; pulse width, $0.05 \mathrm{~s}$; pulse period, $0.2 \mathrm{~s}$ ). HTAB concentration, (a) $10^{-4} \mathrm{~mol} / \mathrm{L}$, (b) $10^{-5} \mathrm{~mol} / \mathrm{L}$, (c) $10^{-6} \mathrm{~mol} / \mathrm{L}$, (d) $5 \times 10^{-7} \mathrm{~mol} / \mathrm{L}$, (e) without HTAB.

electrode in the presence of different surfactants are given in Table 2. In the presence of cationic surfactants, HTAB and $\mathrm{HPB}$, the penetration response occurred on MAA/Au when the surfactant concentration was even as low as $5 \times 10^{-6} \mathrm{~mol} / \mathrm{L}$. Along with increases of HTAB and HPB concentrations, the penetration response appeared more prominent. When their concentration reached $10^{-4} \mathrm{~mol} / \mathrm{L}$, the electrochemical behavior of MAA/Au approached that of a bare Au electrode. The values of $k_{\mathrm{s}}$ and $i_{\mathrm{p}}$ increased along with a decrease of $\Delta E_{\mathrm{p}}$, which indicated that the interaction between a cationic surfactant and the MAA monolayer improved the electronic kinetic reaction. We thus concluded that the reversibility of the redox reaction was enhanced, and the electron transfer on the electrode surface became easier in the presence of a cationic surfactant. As shown in Table 2, a lower value of $k_{\mathrm{s}}$ with a higher value of $\Delta E_{\mathrm{p}}$ was obtained in a probe solution containing $10^{-4} \mathrm{~mol} / \mathrm{L}$ HTAB compared to $5 \times 10^{-5} \mathrm{~mol} / \mathrm{L}$, which implied that the redox reaction has a better reversibility in the latter electrolyte. This may mean that when the concentration of HTAB reached $10^{-4}$ $\mathrm{mol} / \mathrm{L}$, a micelle formed in the solution, which affected the electrode reaction.

As shown in Fig. 6, the value of $k_{\mathrm{s}}$ increased linearly along with the concentration of HPB and HTAB on a MAA-modified electrode, which indicated that the amount of opened

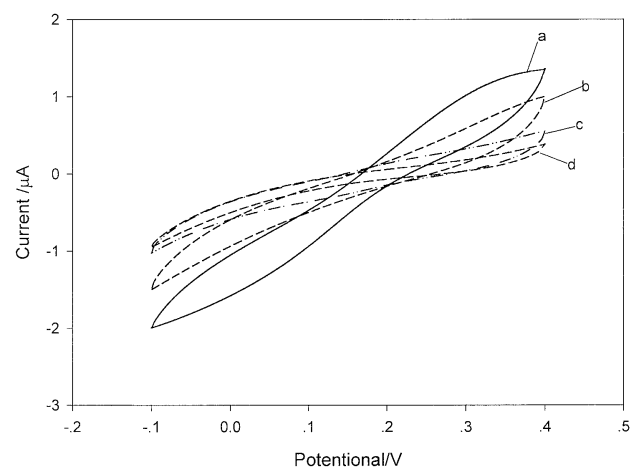

Fig. $8 \mathrm{CV}$ profiles of $\left[\mathrm{Fe}(\mathrm{CN})_{6}\right]^{3-/ 4}$ measured with a NAC modified gold electrode in the presence of SDBS (scan rate, $50 \mathrm{mV}$ $\mathrm{s}^{-1}$ ). (a) Without SDBS, (b) $10^{-4} \mathrm{~mol} / \mathrm{L}$, (c) $10^{-5} \mathrm{~mol} / \mathrm{L}$, (d) $10^{-6}$ $\mathrm{mol} / \mathrm{L}$

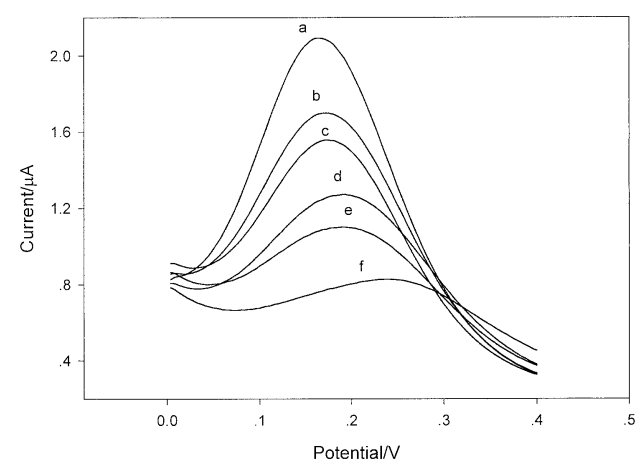

Fig. 9 Differential pulse voltammograms of $1 \mathrm{mM}\left[\mathrm{Fe}(\mathrm{CN})_{6}\right]^{3-14}$ measured with a MAA/Au electrode in the presence of Tween-80 (amplitude, $0.05 \mathrm{~V}$; pulse width, $0.05 \mathrm{~s}$; pulse period, $0.2 \mathrm{~s}$ ). Tween80 concentration, (a) $25 \mathrm{mg} \mathrm{mL}^{-1}$, (b) $10 \mathrm{mg} \mathrm{mL}^{-1}$, (c) $5 \mathrm{mg} \mathrm{mL}^{-1}$, (d) $2.5 \mathrm{mg} \mathrm{mL}^{-1}$, (e) $1.0 \mathrm{mg} \mathrm{mL}^{-1}$,(f) without Tween-80.

"channels" in monolayer was directly related to the HPB and HTAB concentrations in the range from $5 \times 10^{-6} \mathrm{~mol} / \mathrm{L}$ to $10^{-4}$ $\mathrm{mol} / \mathrm{L}$. Moreover, the ionic surfactants adsorbed on the monolayer were in equilibrium with their molecules in the solution. Differential pulse voltammograms of $1 \mathrm{mM}$ $\left[\mathrm{Fe}(\mathrm{CN})_{6}\right]^{3-/ 4}$, measured with a NAC modified gold electrode in the presence of HTAB, are shown in Fig. 7. The same tendency can be seen.

Effect of an anionic surfactant and a non-ionic surfactant. Figure 8 demonstrates $\mathrm{CV}$ profiles of $\left[\mathrm{Fe}(\mathrm{CN})_{6}\right]^{3-14}$ measured with a NAC modified gold electrode in the presence of SDBS. As can be seen, no permeation response was observed. Also, along with an increase of the SDBS concentration, the value of $k_{\mathrm{s}}$ decreased with a decline of the reversibility and the residual current, which shows that the negative surfactant SDBS hindered the access and the reaction of the redox probe by an electrostatic repulsion of the same sign charges.

Differential pulse voltammograms of the MAA/Au electrode in a redox probe solution containing Tween-80 (non-ionic surfactant) are shown in Fig. 9. As can be seen, in the presence of a non-ionic surfactant, the MAA monolayer also showed a permeation response. Along with an increase of the Tween-80 concentration, the response became more obvious. However, the effect of a non-ionic surfactant was not as prominent as ionic surfactants. Tween- 80 showed no significant effect on the NAC/Au electrode. 


\section{Conclusion}

The barrier properties and electron transfer of self-assembled thiol derivative monolayer modified electrodes in the presence of different surfactants were quantitatively investigated by seriate electrochemical experiments. It was found that by changing the surface structure of SAMs, different surfactants could regulate the barrier properties and electron-transfer efficiency in different ways. A positively charged surfactant lowers the electrostatic repulsion between the negative redox probes and negatively charged surface groups of the monolayer, enhancing the reversibility of electron transfer by virtue of increasing the redox probe concentration within the electric double-layer region. A neutral surfactant shows no significant effect, while a negative surfactant hinders the access and reaction of a redox probe by an electrostatic repulsion of samesign charges.

The adsorption model between the surfactant and the thiol derivative monolayers and the suggested methods can be further used to study the penetration property of biomembranes.

\section{Acknowledgements}

We are indebted to the financial support of Doctorate Fund (No. 20020532007) and Key Sci/Tech Res. Project (No. 03123) of Education Department, China.

\section{References}

1. H. O. Finklea, in "Electroanalytical Chemistry-A Series of Advances", ed. A. J. Bard and I. Rubinstein, 1996, Vol. 19, Marcel Dekker, New York, 110 - 335.

2. C. E. D. Chidsey, Science, 1991, 251, 919.

3. S. Arnold, Z. Q. Feng, T. Kakiuchi, W. Knoll, and K. Niki, J. Electroanal. Chem., 1997, 438, 91.

4. C. P. Hsu and R. A. Marcus, J. Chem. Phys., 1997, 106, 584.

5. Q. Cheng and A. Brajter-Toth, Anal. Chem., 1996, 68, 4180.

6. D. Ozkan, A. Erdem, P. Kara, K. Kerman, J. J. Gooding, P. E. Nielsen, and M. Ozsoz, Electrochem. Commun., 2002, 4, 796.

7. K. Ozoemena and T. Nyokong, Electrochim. Acta, 2002, 47, 4035.

8. M. Esplandiu, H. Hagenstrom, and, D. M. Kolb, Langmuir, 2001, 17, 828 .

9. M. D. Porter, T. B. Bright, D. L. Allara, and C. E. D. Chidsey, J. Am. Chem. Soc., 1987, 109, 3559.

10. C. E. D. Chidsey, C. R. Bertozzi, T. M. Putvinski, and A.
M. Mujsce, J. Am. Chem. Soc., 1990, 112, 4301.

11. A. Ulman, Chem. Rev., 1996, 96, 1533.

12. V. Molinero and E. J. Calvo, J. Electroanal. Chem., 1998, $445,17$.

13. Y. M. Zhou, S. Q. Hu, and G. L. Shen, Anal. Lett., 2002, $35,1919$.

14. G. Herzog and D. W. M. Arrigan, Anal. Chem., 2003, 75, 319.

15. U. K. Sur, R. Subramanian, and V. Lakshminarayanan, J. Colloid Interface Sci., 2003, 266, 175.

16. R. Schweiss, C. Werner, and W. Knoll, J. Electroanal. Chem., 2003, 540, 145.

17. K. Takehara, Y. Ide, M. Aihara, and E. Obuchi, Bioelectrochem. Bioenerg., 1992, 29, 103.

18. K. Takehara, Y. Ide, and M. Aihara, Bioelectrochem. Bioenerg., 1992, 29, 113.

19. K. Takehara, M. Aihara, and N. Ueda, Electroanalysis, 1994, 4, 1083.

20. K. Takehara, M. Aihara, Y. Miura, and F. Tanaka, Bioelectrochem. Bioenerg., 1996, 39, 135.

21. C. Yan, A. Naltner, M. Martin, M. Naltner, J. M. Fangman, and O. Gurel, J. Biol. Chem., 2002, 277, 10967.

22. L. A. Augusto, J. Li, M. Synguelakis, J. Johansson, and R. Chaby, J. Biol. Chem., 2002, 277, 23484.

23. D. Zanuy and C. Aleman, Langmuir, 2003, 19, 3987.

24. Y. Gohon and J. L. Popot, Curr. Opin. Colloid Interface, 2003, 8,15 .

25. M. G. Von, S. Vauthey, S. Santoso, and S. G. Zhang, Langmuir, 2003, 19, 4332.

26. B. X. Ye and X. Y. Zhou, Electroanalysis, 1996, 8, 1165.

27. B. Deore and T. Nagaoro, Anal. Sci., 2001, 17, 1691.

28. P. Bianco and J. Haladjian, Electrochim. Acta, 1997, 16, 587.

29. S. Boussaad and N. J. Tao, J. Am. Chem. Soc., 1999, 121, 4510.

30. Y. C. Tsai, J. Davis, and R. G. Compton, Fresenius J. Anal. Chem., 2000, 368, 415.

31. Y. J. Liu, Z. H. Zhang, L. H. Nie, and S. Z. Yao, Electrochim. Acta, 2003, 48, 2823.

32. J. Wang, B. Z. Zeng, C. Fang, and X. Y. Zhou, J. Electroanal. Chem., 2000, 484, 88.

33. E. Boubour and R. B. Lennox, Langmuir, 2000, 16, 4222.

34. E. Boubour and R. B. Lennox, Langmuir, 2000, 16, 7464.

35. E. Boubour and R. B. Lennox, J. Phys. Chem. B, 2000, 104, 9004.

36. V. Molinero and E. J. Calvo, J. Electroanal. Chem., 1998, 445, 17.

37. M. D. Porter, T. B. Bright, D. L. Allara, and C. E. D. Chidsey, J. Am. Chem. Soc., 1987, 109, 3559.

38. C. Meiller, P. Cuendet, and M. Gratzel, J. Phys. Chem., 1991, 95, 877 . 